\section{Political feud blocks funds}

A DISPUTE between the Italian Space Agency (ASI) and its advisory committee over how to spend the agency's budget is blocking the flow of tens of millions of dollars to space scientists. The political battle has delayed the analysis of data from orbiting instruments, jeopardized Italy's commitments to its international partners and damaged morale within the space science community.

The impasse began last May, when the science advisory committee to (ASI) put forward a five-year plan. The plan covered collaborations with its neighbours in the European Space Agency (ESA), the United States and the former Soviet Union, as well as a national programme.

ASI, created in 1988 , is required by law to spend 15 per cent of its budget on research. For 1991 that was 68 billion lira (US\$55 million). And the Science Committee, which is elected by ASI, is supposed to recommend how that money should be spent. But last autumn that process broke down.

Between May and November, ASI reduced the amount going to science by more than half. It did so in two ways. ASI took out its contribution to ESA before computing the 15-per-cent share for science. It also allocated some 20 billion lira to projects on an X-ray satellite due to be launched next year.

Angered by this erosion of its responsibilities, the Science Committee refused to accept this reduced budget, saying it would damage the long-term plan. Instead, it submitted a proposal for 74 billion lira, a bit higher than its 15 -per-cent share, which ASI rejected. ASI is now waiting for a new proposal in line with available funds.

The debate is not just about money. The impasse reflects unresolved questions about the proper relationship between ASI and the Science Committee. Many scientists believe that the only solution is to dissolve the committee and start again.

Committee chairman Remo Ruffini, of the University of Rome, argues that any sizable reduction in projects funded would threaten Italy's future in space research. Although he says he is prepared to reduce his proposal by 20 per cent, he is determined to continue the committee's fight for "the constitutional right to have their full budget returned".

But some committee members feel that Ruffini's hard line threatens Italy's future in space science, and that what is needed is a compromise offer that ASI would accept. Committee member Franco Pacini of the Florence Observatory, who has called for Ruffini's resignation, says that the time to oppose the budget cuts was last summer, when it was announced. Instead, he says, the committee adopted a head-in- the-sand attitude that damaged its effectiveness. But he also feels that political and organizational problems within ASI have blurred the financial picture unnecessarily.

Criticisms of the Science Committee are widespread. Unlike advisory bodies in other countries, Italy's committee contains a mixture of pure and applied scientists with differing interests. In addition, ASI has been criticized for letting politics influence its selection of members. Scientists also feel that the absence of a formal peer review system and any mechanism for public accountability leaves them with too little representation.

Giovanni Bignami, of the University of Cassino, says that ASI should take immediate steps to make sure that the Science Committee works because it has ultimate responsibility for the projects it funds. Otherwise, he argues, the Committee should be replaced by an advisory body similar to that used by ESA and the US National Aeronautics and Space Administration (NASA), which have appropriate peer review systems and which publish their decisions.

Bignami, principal investigator for the European Photon Imaging Camera, an instrument on the ESA cornerstone mission XMM, is frustrated by the long delay in funding. Although salaries are independent of ASI funding, the impasse has meant that no money is available for travel and hardware.

The cost to major space science projects is very high. Pier Luigi Bernacca is principal investigator in Italy for the HIPPARCOS project, a satellite that is producing data for a European consortium, the Fundamental Astronomy by Space Technology (FAST). Bernacca says that the backlog of one year's worth of data is causing problems for his consortium partners, and he blames those responsible for holding back funds for "putting their personal views above science".

Giancarlo Noci of the University of Florence, whose contribution to the Solar and Heliographic Observatory (SOHO) mission was reduced because of the funding difficulties, says that the damage can never be repaired fully. The delay has raised not only the cost of the project but also the risks involved by forcing researchers to abandon many of their test models.

The situation is also harmful to Italy's international reputations. In a field where international collaboration is essential, this is both embarrassing and destructive.

In the meantime, ASI and the Science Committee are meeting regularly in the hope of reaching a settlement - forced or otherwise - by May. At the very least, release of some interim funding is expected.
New science institute Tokyo

JAPAN's new International Institute for Advanced Studies (IIAS), a sort of Japanese equivalent of the Institute for Advanced Studies in Princeton, New Jersey, continues to break new ground in Japan by attracting large amounts of financial support for basic academic research from private industry and philanthropists.

The latest contribution comes from Shimadzu, a Japanese scientific instrument maker. It has just agreed to donate $¥ 400$ million (US\$3 million) to IIAS over five years in memory of Shosaku Numa, one of Japan's leading molecular biologists who died in February (see Nature 356, 193; 1992). The money will be used by a team of three researchers led by Y. Kubo, a former research associate of Numa's, to continue Numa's research on acetylcholine receptors and ion channels, says Saburo Fukui, chairman of the IIAS planning committee.

Japan has few private foundations that support research, and most of them tend to be small and confined by bureaucratic government regulations to narrow fields. But IIAS seems ready to break out of that mould, assuming that the Japanese economy recovers from its recent problems and science is seen as an important national priority.

The institute has so far raised more than $\$ 5,200$ million (about $\$ 40$ million) from private contributions, and institute organizers have set the ambitious goal of increasing this to $¥ 50,000$ million by 1994 . That goal is tied in part to the institute's planned move next year from temporary offices in Kyoto to the heart of the new Kansai Culture and Science City.

Much of the money already pledged has come from private individuals in the form of cash, real estate and stocks. For example, the late Kazuma Tateishi, founder of Omron Corporation, a manufacturer of control system components, donated one million personal shares in his company to support construction of the new IIAS complex.

The Kansai science 'city' consists at present of only a handful of isolated institutes set in mountains between Kyoto, Nara and Osaka. But the city is expected to have a population of 380,000 people when completed next century after an estimated investment of $¥ 20,000-¥ 25,000$ million.

IIAS is intended to be the 'brain' of the city. It will have a changing population of about $\mathbf{4 0}$ senior academics drawn from all over the world, plus supporting administrative staff. Although research in the life sciences will be a central focus, Fukui says, the institute will also support work in philosophy and mathematics. Topics will be chosen by its faculty as well as by outside contributors from both industry and the government. David Swinbanks 